\title{
THE SPECTRAL ANALYSIS OF SYLLABLES IN PATIENTS USING DENTURES
}

\author{
Petr Jindra ${ }^{\mathrm{a}}$, Miroslav Eber ${ }^{\mathrm{a}}$, Josef Pešák ${ }^{\mathrm{b}}$
a $2^{\text {nd }}$ Clinic of Stomatology, Faculty of Medicine, Palacky University, Palackeho 12, 77200, Olomouc, Czech republic
${ }^{b}$ Department of Medical Biophysics, Faculty of Medicine, Palacky University, Hnevotinska 3, 77515, Olomouc, Czech
Republic,e-mail: pjindra@seznam.cz

Received: August 10, 2002

Key words: Dentures / Speech / Voice

\begin{abstract}
Changes in the oral cavity resulting from the loss of teeth and the ensuing reconstruction of a set of teeth by dentures (partial or complete) may cause changes in the speech and voice of the patient. The aim of the present investigation was to study the changes in speech and voice in patients suffering from teeth loss and the degree of speech improvement using dentures. Voice and speech parameters of a set of tested syllables were analysed in 10 patients at the $2^{\text {nd }}$ Clinic of Stomatology. The analysis was carried out by means of an FFT, SoundForge 5.0 programme. Differently expressed acoustic changes in both consonants and vowels were ascertained in a percentage of the patients under examination. These concerned especially the sibilant ("s", "š"), labiodental ("f", "v") and vibrating ("r", " $\breve{\mathrm{r}}$ ") consonants. Changes in the FFT spectrum and air leakage in constrictive consonants were also found. In some patients the vowels, especially the closed ones ("i", "u"), may change their fundamental frequency and show noise admixture manifested as a blurred delimitation of the formants. A denture should, inter alia, render it possible for the patient to produce the same articulation to which he/she had been accustomed before the loss of teeth. For the construction of dentures the most important factors from a phonetic point of view appear to be the following: overbite, overjet, the height of the plate, the thickness of the palatal material, the incisor position, and the modelling of the ruga palatina on the hard palate. In case of wrong denture construction the acoustic changes may continue, resulting in the patient's stress load dependent upon sex, age, psychic condition and seriousness of the problem.
\end{abstract}

\section{INTRODUCTION}

Changes in the oral cavity resulting from the loss of teeth (due to parodontopathy, caries dentis, injuries, etc.) and the resorption of the processus alveolaris maxillae, or the processus alveolaris mandibulae, may cause defects in the patient's voice and speech. The function of dentures (partial or complete), besides having aesthetic and masticatory functions, is to eliminate the above defects.

From the functional point of view, the oral cavity (cavum oris) is part of the vocal apparatus. The voice is produced in the larynx with the aid of the vocal chords vibrating due to the expiratory air flow. The frequency of the fundamental laryngeal tone is dependent on the vocal chord tension. The fundamental laryngeal tone is then modulated in the resonance cavities (the Purkyně supra-vocal-cord space, the oral cavity), their shape conditioning the vowel formants ${ }^{1}$.

According to the position of the tongue in the oral cavity vowels are divided into high $(\mathrm{i}, \mathrm{u})$, central $(\mathrm{e}, \mathrm{o})$ and low (a) - the so-called Hellwag triangle. Consonants are such sounds of the human speech in the for- mation of which an obstacle produced by the speech organs hinders the passage of the expiratory air flow. The speech organs include the tongue, palate, alveolar processes, gums, teeth and lips. According to the place of their formation consonants ${ }^{2}$ are divided into bilabial (p, b, m), labiodental (f, v), alveolar front (t, d, n, c, s, z,

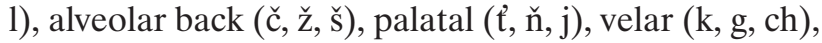
and laryngeal consonants.

Dentures must be made lege artis so as to render it possible to produce voice and speech without deficiencies. If they are inaccurately made, then the deficiencies in the patient's voice and speech may continue and cause discontent. About 25\% patients in clinical dentistry are considered ${ }^{3}$ to suffer from temporary or permanent changes in articulation due to the application of removable dentures. Therefore it is of great importance for a dentist making a denture to keep this aspect in mind.

The aim of the present investigation has been to study the changes in voice and speech in patients suffering from the loss of teeth and the degree of speech improvement resulting from the application of a denture. 


\section{METHODS}

Voice and speech parameters in a set of tested syllables were analysed in 10 patients of the $2^{\text {nd }}$ Clinic of Stomatology in Olomouc. The sequence of syllables was as follows: "si, že, ša, ta, da, ře, ra, fa, vi, pa, bo". Each syllable was pronounced by the respective patient several times, the whole sequence being pronounced and recorded with dentures and without them. At the same time the patient's anamnesis was taken with regard to subjective problems when speaking with the removable dentures.

For recording we made use of the MZ-R3 minidisc and a set with AKG C 10005 microphone, the Behringer MX 802 A mixing table, and the Sennheiser HD 250 linear II headphones. The FFT (Fourier Analysis) was carried out by the means of the SoundForge 5.0 program with the Delta 66 sound card. Individual recordings in the subjects under investigation were carried out under the same acoustic conditions in the standard examination room of the clinic under constant acoustic properties of the room (Fig. 1.).

In the set of patients under examination there were 5 males and 5 females aged between 58-81 years. From the point of view of the dental prosthesis used complete denture or partial denture substituting the upper incisors were applied in the maxilla. The complete or partial dentures were applied in the mandible.

\section{RESULTS}

In some patients under investigation we found differently expressed acoustic changes in consonants as well as in vowels when speaking without dentures. The applied denture considerably eliminated these defects. In some cases, however, permanent changes were found.

This is particularly true for the sibilants belonging to the alveolar consonants according to the place of their articulation. Fig. 2 shows the record of the "si" syllable in a female patient first without dentures and then with them. The figure clearly shows decrease in the upper limit of the noise zone and decrease in the maximum towards lower frequencies when articulating without dentures. These changes can be easily heard. When articulating with dentures the above-described defect was corrected. Similar phenomena were found in all the patients of the set under examination.

Similarly a change in the quality of the "f $\mathrm{f}$ " consonant occurred in 6 patients of the set. Fig. 3 gives a spectral analysis of the "fa" syllable in one patient, articulated without dentures and with them. When articulating without dentures there occurred total disappearance of the frequencies higher than $3.5 \mathrm{kHz}$. When articulating with dentures an increase in the frequency zone up to $13 \mathrm{kHz}$ took place.

In all patients articulating without dentures the vibrating consonants ("r" and "řr" - rotacismus bohemicus) showed a change in the noise characteristics in the frequency zone. Fig. 4 shows the "ř patient with dentures, articulating both with the removable denture and without it. Different representation of the frequencies in the noise zone corresponding to the "řr" consonant can be easily seen.

The effect of the loss of teeth and the reconstruction of the set by dentures on a patient's voice relates to changes in the delimitation of the formants of the individual vowels.

Changes in the formant delimitation can be clearly seen for example in Fig. 2, giving the recorded speech of a female patient pronouncing the "si" syllable. When articulating without dentures the resultant spectral analysis shows frequencies higher than $3.5 \mathrm{kHz}$, not belonging to the spectrum of the Czech vowel "i". When articulating with dentures the oral formant is delimited more clearly and frequencies above $3.5 \mathrm{kHz}$ are less frequent.

From the anamneses taken it has been deduced that subjective temporary or permanent problems after applying the denture were felt in four patients of our set. The patients mentioned increased neurosis when speaking in public, problems concerning the articulation of the sibilant sounds, and decrease mobility of the lips in speech, resulting from the application of removable denture.

\section{DISCUSSION}

The results obtained are in full agreement with those contained in the hitherto published papers ${ }^{3-6}$. The changes in voice and speech resulting from the loss of teeth and the reconstruction of a set of removable dentures have also been studied and described in Polish ${ }^{7}$, Hungarian $^{8}$, and Japanese ${ }^{9}$.

For practical dentistry work Wisser et al. recommend $^{3}$ a special attention to the bilabial ("p, b"), labiodental ("f, v"), alveolar ("t, d"), and sibilant ("s, sch") consonants. They describe a defect in the pronunciation of the sibilants when an excessive leakage of the air flow takes place through a sibilant slot between the tongue and the palatal section of the dentures. A similar problem was also mentioned by three patients of the set under our investigation.

\section{CONCLUSION}

In the present research work we have dealt with the changes in voice and speech resulting from the loss of teeth and the speech improvement after the reconstruction of the set by removable denture (complete or partial). Changes in the articulation of the consonants "s, $\mathrm{f}$, $\mathrm{r}$, and $\check{\mathrm{r}}$ " were found in a set of 10 patients at the $2^{\text {nd }}$ Clinic of Stomatology in Olomouc.

For eliminating speech defects it is necessary to ensure perfect shaping of removable dentures. One may assume that voice and speech are affected first of all by 


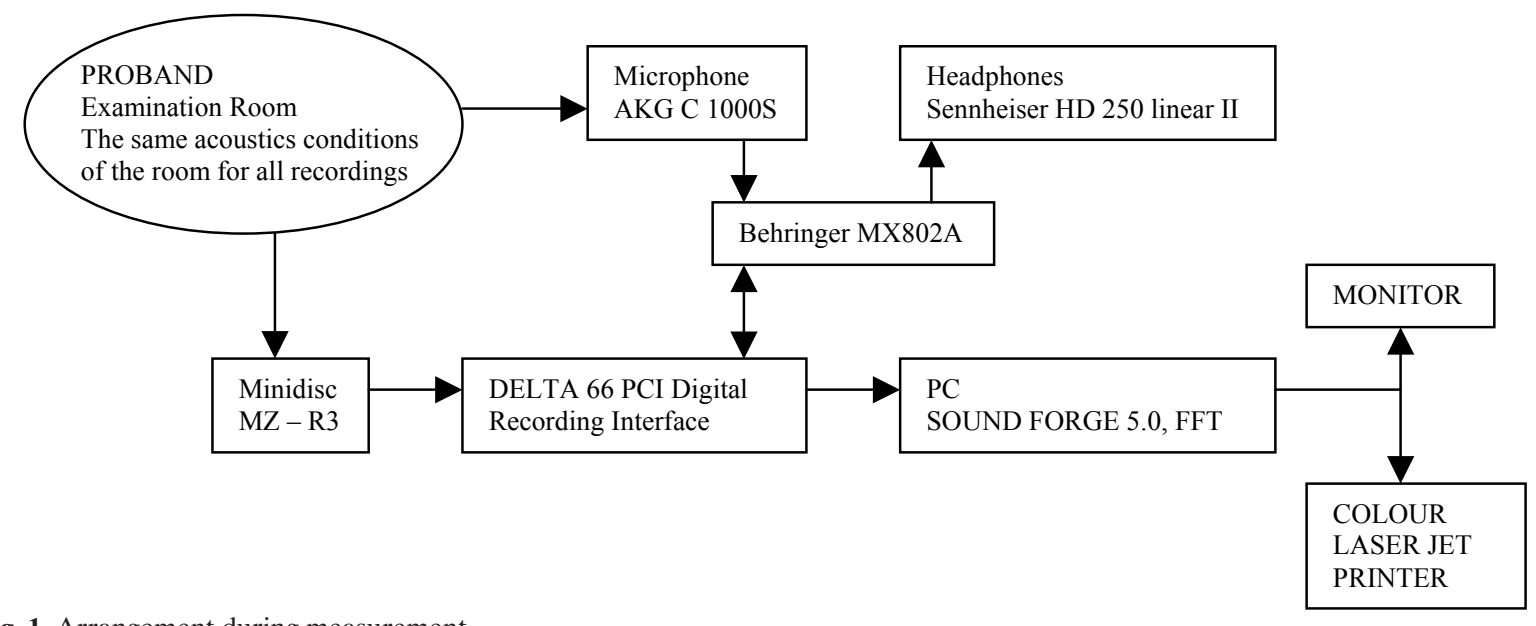

Fig. 1. Arrangement during measurement
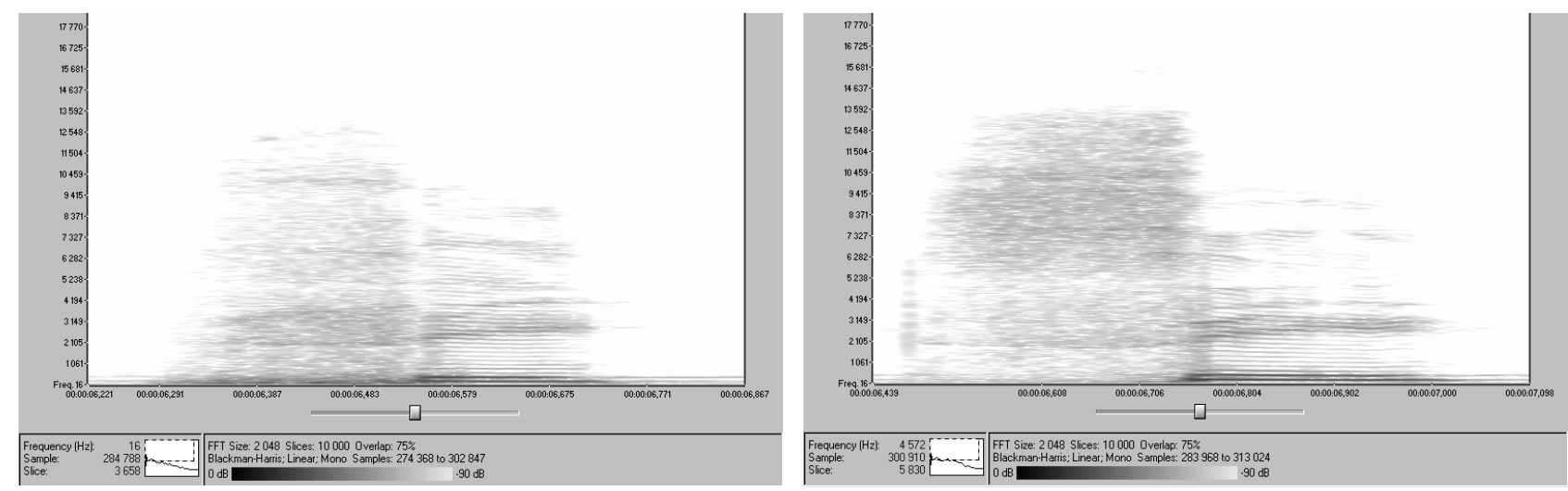

Fig. 2. FFT, "si" syllable, without denture, with denture
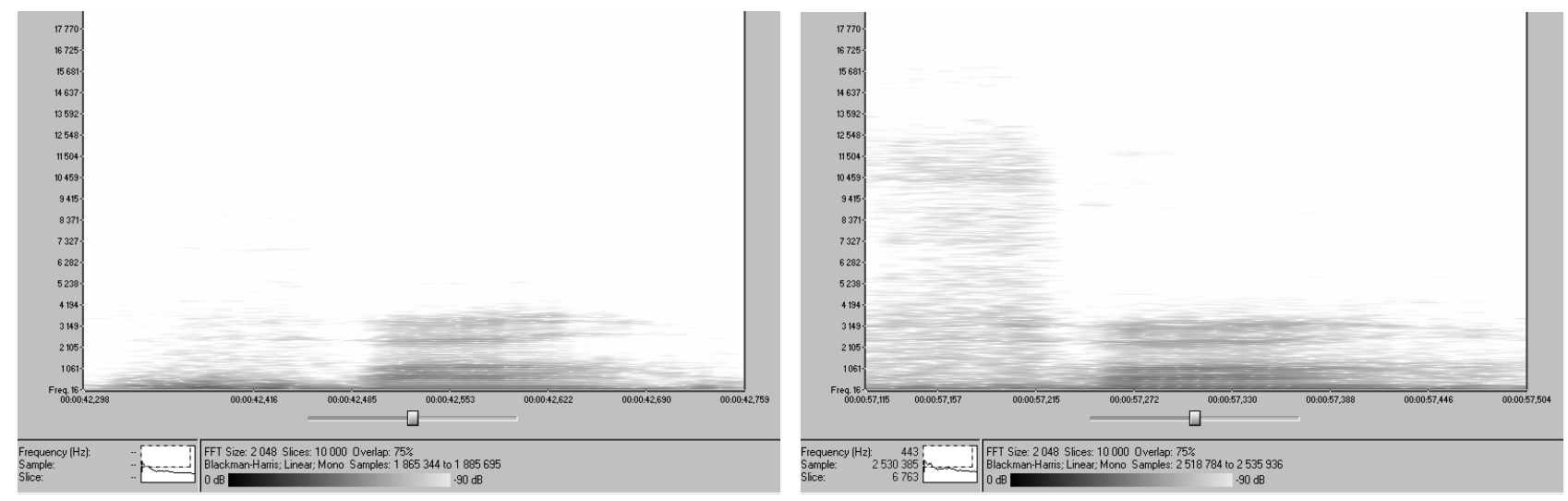

Fig. 3. FFT, "fa" syllable, without denture, with denture 

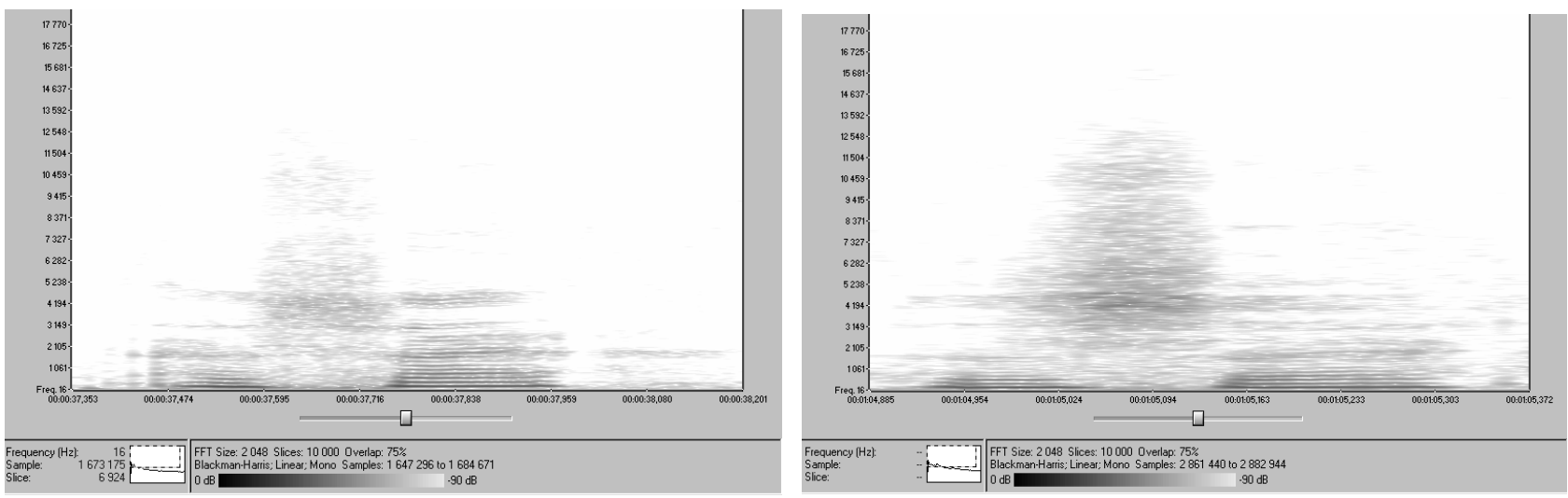

Fig. 4. FFT, "ř̀e" syllable (rotacismus bohemicus), without denture, with denture

the parameters of overbite, overjet, the thickness of the palatal section of the plate, the incisor position, the height of the plate, and the modelling of the ruga palatina on the hard palate.

If defective dentures are made, speech defects may be of a permanent character and result in the patient's stress load dependent upon sex, age, profession, psychic condition and seriousness of the problem.

For practical dentistry work one may recommend drawing the patient's attention to possible speech problems after the application of removable dentures (immediate or permanent). It is also important to call the patient's attention to the fact that a certain time will be necessary for getting accustomed to the new dentures and mastering one's speech perfectly.

\section{ACKNOWLEDGEMENS}

The research work has been carried out under the sponsorship of the research task NK6720-3/2001 "The relation between the quality of complete dentures to the general health of geronts" and the research task CEZ: J114/98:N30000018 "Integrated study of voice and speech".

\section{REFERENCES}

1. Titze IR (1994) Principles of voice production, Prentice Hall, New Jersey.

2. Hála, Sovák (1962) Voice, speech, hearing, SPN, Praha.

3. Wisser W, Lotzmann U (2000) Zur instrumentalphonetischen Analyse der Lautbildung an Zahnersatz, ZWR, No.10, 109. Jahrg., p. $538-543$.

4. Seifert E, Runte C, Riebandt M, Lamprecht-Dinnesen A, Bollmann F (1999) Can dental prostheses influence vocal parameters?, J Prosthet Dent, 81 (5), 579-85.

5. Seifert E, Runte C, Riebandt M, Lamprecht-Dinnesen A, Bollmann F (1999) Effect of dental prosthesis on the voice, HNO, 47 (5), 485-9.

6. Runte C, Lawerino M, Dirksen D, Bollman F, Lamprecht-Dinnesen A, Seifert E (2001) The influence of maxillary central incisor position in complete dentures on /s/ sound production, J Prosthet Dent, 85 (5), 485-95.

7. Ksiazkiewicz-Jozwiak B, Wszolek W (1987) Spectral assessment of the degree of speech signal deformity in patients wearing complete denture, Protet Stomatol, 37 (2), 73-9.

8. Kaan M, Bolla K, Keszler B (1993) Speech characteristics of persons wearing full upper and lower prostheses, Fogorv Sz, 86 (2), 45-53.

9. Horiuchi M (1989) Studies on influences of artificial palatal plates on pronunciation, Nippon Hotetsu Shika Gakkai Zasshi, 33 (4), 863-77.

10. Gillis RE, Leonard RJ (1983) Prosthetic treatment for speech and swallowing in patients with total glossectomy, J Prosthet Dent, 50 (6), 808-14. 